\title{
Adapting Dialectical Behavior Therapy for Patients with Binge Eating and Bulimia Nervosa Disorders
}

\author{
Moustafa Hassan Yacoub, Ph.D \\ Institute of Arab Research \&Studies \\ League of Arab States,
}

Cairo

\begin{abstract}
:
It has been shown that Dialectical Behavior Therapy (DBT) is an effective treatment for patients with borderline personality disorder (BPD), suicidal, and self-injuries behaviors. However, it extends to involve treating various disorders. Studies that conducted on patients with binge eating and bulimia nervosa have demonstrated promising findings in adapting DBT to treat patients with binge eating and bulimia nervosa. This article provides an overview for DBT philosophy and applying this therapeutic approach for patients with binge eating and bulimia nervosa, moreover, it introduces some intriguing studies that offered critical results for DBT interventions.
\end{abstract}

Key words: DBT, Binge Eating, and Bulimia Nervosa

Binge-eating disorder is an eating disorder marked by repeated episodes of binge eating and a feeling of loss of control. The diagnosis is based on a person's having an average of at least binge- eating episodes per week for six months. Bulimia nervosa is an eating disorder marked by consumption of large amounts of food at one time (binge eating) followed by a behavior such as self-induced vomiting, use of laxatives, excessive, exercise, fasting, or other practices to avoid weight gain Like those with binge-eating disorder, people with bulimia nervosa compulsively gorge themselves like those with anorexia, people with bulimia desperately want to be thin and resort to purging to reach this goal (Insel\& et al.2004,p.547)

Bulimia nervosa and binge-eating disorder are characterized by recurrent bingeeating episodes during which the individual feels out of control while consuming abnormally large quantities of food (Mcintosh\&et al, 2007,p. 325). Bulimia nervosa involves frequent episodes of binge eating, almost always followed by purging and intense feelings of guilt or shame. Purging is a way for bulimics to 
exert control over their weight or shape. Binge-eating disorder is different from bulimia nervosa in that binge eaters don't usually purge and they are often overweight or obese. Also, to obtain a diagnosis of BED, a person must have engaged in the behavior for longer than three months. As with bulimia nervosa, those who binge less frequently may also need treatment (Agras\&Apple,2008,p.5). Patients with bulimia nervosa generally are not eating normally. Many fast for extended periods of time, make unwise food choices, and/ or are overly restrictive in their diets when not binge eating (Yager\&Powers,2007,p.173).

Bulimia nervosa has five criteria in DSM-5 recurrent episodes of binge eating characterized by both of the following eating in a discrete period of time and a sense of lack of control over eating during the episode, recurrent in appropriate compensatory behaviors in order to prevent weight gain both of binge eating and inappropriate compensatory behaviors both occur on average at least once a week for three months, self-evaluation is unduly influenced by body shape and weight, and the disturbance does not occur exclusively episodes of anorexia nervosa.

Otherwise, binge-eating disorder has more one diagnostic criteria such as recurrent episodes of binge eating, a sense of lack of control over eating during episode, the binge eating episodes are associated with three or more of the following (eating much more rapidly than normal, eating until feeling uncomfortably full, eating large amounts of food when not feeling physically hungry, eating alone because of feelings embarrassed by how much one is eating, feeling disgusted with oneself, depressed, or very guilty afterward), marked distress regarding binge eating is present, the binge occurs on average at least once a week for three months, and the binge is not associated with the recurrent use of inappropriate compensatory behavior as in bulimia nervosa and does not occur exclusively during the course of bulimia or anorexia nervosa (APA,DSM-5,2013,pp.345\&350).

\section{DBT and Dialectical Philosophy:}

The notion of process, activity, event, or change has an inextricable relation to the nature and meaning of dialectic. In ancient philosophy, dialektike, derived from the Greek dialegein, meaning to " converse"," argue" or " discourse" 
involved a conventional method of argumentative exchange (Mills,2010,p.34). Dialectical theory has an event sequence of thesis/ antithesis, conflict, synthesis, and thesis/antithesis. It has a generative mechanism of pluralism, confrontation, and conflict (Boonstra,2004,p.179).

Dialectics originated with ancient philosophers who argued that there is no such an absolute position. In other words, each position on a continuum has its own truth and its own wisdom, and what seem like opposites or contradictions are related to one another. In dialectics, the search for relative truth is what leads to synthesis and balance. This synthesis and balance is particularly important when people get caught in extremes of emotions, thoughts, and behaviors (Pederson,2013,p.5).

Dialectical philosophy rests on assumptions that guide its application. First, dialectics recognize inherent contradictions and tensions that arise within us, between us, in situations, and in the world. Rather than allowing these positions to negate each other, the philosophy seeks synthesis, balance, and flow, transforming the crystallization of opposites into fluid movement. This movement represents the second assumption, that change is continual and will lead to new contradictions and crises. The goal of dialectics is responsive synthesis to meet demands and be effective ( Pederson,2015,p.31).

Dialectical Behavioral Therapy (DBT) was originally developed to treat suicidal and self-harm behaviors in individuals with borderline personality disorder (Brodsky\& Stanely, 2013). It was specifically developed to treat both the biologically and environmentally produced characteristics of borderline personality disorders. In DBT approach, cognitive and behavioral strategies are used to help the client develop skills in emotional regulation, distress tolerance, and interpersonal effectiveness within the context of a therapeutic environment that strongly emphasizes the interpersonal skills of empathy, reflection, and validation (Sue\&Sue,2008,p.266).Also, Pederson(2013) mentioned that DBT developed by Marsha M. Linehan for highly suicidal and self-injurious people in her research setting, it is safe to say that this approach has been widely disseminated into community settings, both in her original treatment model (Standard DBT) and in many effective adaptations (p.2). DBT is the only program that focuses so primarily on the link between emotion dysregulation and binge eating. Central to DBT is that individuals turn to food to self-soothe,numb, and avoid emotional discomfort because food " works" temporarily despite its longerterm negative consequences (Safer\& et al,2018,p.8). 
Dialectical Behavioral Therapy (DBT), a psychosocial treatment that combines cognitive-behavioral theory and methods with eastern meditative principles and practices, has changed this picture significantly (Norling\&Kim,2010,p.877).

\section{Biosocial Theory:}

The Biosocial theory that biology and environment are co-conspirators that can overwhelm coping systems in vulnerable individuals when perceived or actual invalidation produces sufficient tension- also aligns itself with the bio psychosocial perspective associated with social work. By assigning a biological/environmental rather than a motivational or personality genesis to dysregulatory disorders, the biosocial perspective may serve to moderate that pervasive shame often felt by these clients that can further handicap treatment (Stone,2007,p.149).

The biosocial theory stresses reciprocity between Emotional Vulnerability and Invalidating Environmental experiences. Specifically, emotionally sensitive individuals often place unreasonable demands on others, which increases the likelihood that others will respond with invalidation. Conversely, contact with pervasively invalidating environments generates emotional sensitivity even among individuals who are less vulnerable. The consequence is a failure to learn how to modulate emotions effectively (Burckell\&McMain,2010,p.208).

Emotional Vulnerability refers to high emotional sensitivity (i,e, low threshold for having and emotional reaction) and reactivity (i,e, intense emotional reactions), and slow return to emotional baseline. An invalidating environment refers to environments that communicate to individuals that their inner and outer experiences (emotional, behavioral, and cognitive) are incorrect, inaccurate, or inappropriate. An environment, which may include parents, siblings, teachers, coaches, therapists, and others, may begin as invalidating or transform over time in response to stress from the emotionally sensitive individual ( Klein\& Miller,2011,p.207).

\section{Treatment Hierarchy:}

DBT's target hierarchy and the client's case formulation provide guidelines about what to work on and how to allocate your time strategically. What's required is that you treat the highest priority target sufficiently but this need not take up the entire session. To work efficiently, you focus attention on the controlling variables that are common across target behaviors and weave change strategies together to 
address these common processes (Koerner,2012,p.76). (Weder,2010,p.183) mentioned that ,Individual therapists follow this hierarchy during sessions, to keep track of the client's progress and treatment goals, and to make sure that important problem behaviors are not missed during sessions. The following are the four components of DBT's target hierarchy:

1. Reducing life-threatening, self-harm, or suicidal behaviors.

2. Reducing therapy interfering behaviors.

3. Reducing quality of life-interfering behaviors.

4. Improving the use of adaptive skills.

\section{Treatment Stages:}

DBT has several stages of treatment based upon the problems that need to be addressed. One stage is completed before moving to the next. However, there are times when patients move from a later stage back to an earlier stage depending on their problems at the moment (Brodsky\&Stanley,2013,p.75). Further, (Cottone,2017,p.264) mentioned that DBT has four stages: Stage 1: moving from being out of control of one's behavior to being in control;stage 2: moving from being emotionally shut down to experiencing emotions fully ; stage 3: building ordinary life, solving ordinary life problems; stage 4: moving from incompleteness to completeness/ connection.

\section{Treatment Models for Binge Eating and Bulimia Nervosa:}

Chen and his colleague (2018) referred to DBT models for binge eating and bulimia nervosa in the following:

The DBT for BED/BN combines elements of individual psychotherapy and group skills training from standard DBT. Dialectical behavior therapy for BEN/BN incorporates chain analysis strategies typically conducted in individual psychotherapy in standard DBT, with skills training, typically offered in a group format in standard DBT. The format of each session is divided evenly. The first half, consisting of 50-60 minutes if treatment is carried out in a two hour group format or 25-30 minutes individual format, is devoted to homework review and includes discussion of client diary cards and chain analyses (motivation and skills strengthening). During this review, each group member has between five and ten minutes to report on his or her use of new skills in the past week and to describe 
specific successes or difficulties in applying the skills to replace the targeted problem eating behaviors. The length of time each member has for homework review varies given the total duration of the session (which may be two hours or two hours and half) and the number in attendance so that sufficient time is available for everyone to share. Group members are encouraged to help one another identify solutions to problems encountered in using the skills and to "cheerlead" efforts made. Separated by a 5-10 minute break when using a group format, the second half of each session is devoted to teaching new content and practice of new skills ( Chen \& et al,2018,341).

Accordingly, DBT has two models individual and group skills training. in individual therapy the therapist has to run the session in DBT hierarchal system and build constructive therapeutic relationship with patients, however, therapists have to care about introducing group training skills in group sessions which follow psych educational method.

\section{DBT Skills:}

DBT is composed of four groups of skills or modules: Mindfulness, Distress Tolerance, Emotions regulation, and Interpersonal Effectiveness (Lozier,2018,p.13). Dr. Linehan formulated strategies to help patients women tolerate their pain while working toward building " a life worth living". She developed a skills training program encompassing four modules that teach specific skills in the areas of mindfulness, interpersonal effectiveness, distress tolerance, and emotion regulation and self-management. These skills teach people how to balance their lives without resorting to self-destructive behaviors (Porr,2010,p.4).

\section{Mindfulness:}

Mindfulness involves learning to control the focus of attention, not the object being attended to (e.g, observing a thought as a thought or an emotion as an emotion, without an attempt to change the thought or emotion) (Baer,2006,p.224). Mindful eating involves bringing your full attention and awareness to the food you are eating. Binge eating is a mindless activity during which you shut out or deny full awareness of the consequences of your behavior. Mindful eating involves helping you access your wise mind when you are eating, when you practice mindful eating, you are using the skills of observing along with adopting a nonjudgmental stance and focusing on one thing in the moment (Safer\&et al,2018,p.156). 


\section{Interpersonal Effectiveness:}

The interpersonal effectiveness module is helping individuals develop good interpersonal connections and support. The importance of communication and relationships cannot be overemphasized. Practice with developing interpersonal skills is the key as developing healthy interpersonal behaviors might take a lot of practice. Role play, also called behavioral rehearsal, can help clients practice interpersonal skills (Belmont,2013,p.88).

\section{Emotion Regulation:}

One important set of skills taught in DBT is emotion regulation skills. These skills can help you improve the way you manage or regulate your emotions. Emotion regulation skills also can be tremendously useful even if you don't have any specific emotional disorder (Chapman\& et al,2011,p.39).

\section{Distress Tolerance:}

Distress tolerance is taught in DBT through acceptance or change procedures, or both. Acceptance techniques assist clients in enduring difficult situations and emotional states without altering the associated aversive private event. Change procedures generally involve regulating private events to a level where chances of engaging in goal-oriented activities while the private event is present are increased," distress tolerance" is trained through acceptance and defusion (treating private events nonliterally), and is done in the service on one's values ( meaningful areas of life) (Twohig\&Peterson,2009 ,p.267).

\section{Treatment Strategies:}

DBT employs five sets of treatment strategies to achieve behavioral targets :(1) dialectical strategies which involved balancing treatment strategies, teaching dialectical behaviors, allowing natural change, playing devil's advocate, activating wise mind, entering the paradox, making lemonade out of lemon, and extending,(2) validation strategies, so validation is a communication that affirms what is true, accurate, or valid in a client's beliefs, emotional reactions, and behavior it also increases clients' motivation. There are different ways/ levels for validation each depends on targeting behaviors starts from 1-6 levels, Levels 1-3 are typical of standard psychotherapeutic listening skills, level 4 refers to validating client's behavior, level 5 is given in accordance with the present context or normative functioning, and level 6 which referred to radical genuineness. and 
(3) problems-solving strategies involve behavioral analysis, solution analysis, problem solving procedures(e,g, contingency process, skills training, exposure, and cognitive modification);(4) stylistic strategies include two quite different styles of communication (reciprocal and irreverent communications); and (5) case management strategies have three major strategies (consultation to the patient strategy, environmental intervention, and consultation team meeting) (Linehan\&etal,2007,p.56_70;Swales\&Heard,2009,p.129;Linehan\&Wagner,2006,p p.136- 137;Linehan\&Mazza,2008,pp.395-398).

\section{Dialectical Views for Eating Disorders:}

Marra (2005) introduced a unique analysis for dialectics in eating disorders he referred to this:

"Eating disorders involve central issues of identity, accept ability, indulgence or urge versus inhibition, self-control versus helplessness, and the fundamental acceptability of the individual to self and to society. The patient acts as if their hunger will destroy them as well as others. The conflict is between urge and selfcontrol, with less attention focused on solution-focused coping (the behaviors that will help them to accomplish their goals). High emotional arousal results from their self-loathing rather than from food or eating food. Food is simply the focus of attention around which the under lying emotional dread and want dance" (p.128)

He also summarized these thoughts in a systematic manner

\section{Dialectics with Eating Disorders}

\begin{tabular}{ll}
\hline My body is disgusting & My body can be improved. \\
$\begin{array}{l}\text { I don't deserve } \\
\text { nourishment }\end{array}$ & $\begin{array}{l}\text { Food is the only known } \\
\text { nourishment }\end{array}$
\end{tabular}

$\begin{aligned} & \text { People will love me for } \\ & \text { my appearance }\end{aligned}$
$\begin{aligned} & \text { Food is my consistent } \\ & \text { enemy }\end{aligned}$




\section{$\longrightarrow \quad$ My self is not beautiful}

I have a secret

Food is my only

consistent friend

\begin{abstract}
My needs are important

People would love me if
\end{abstract} my body was beautiful
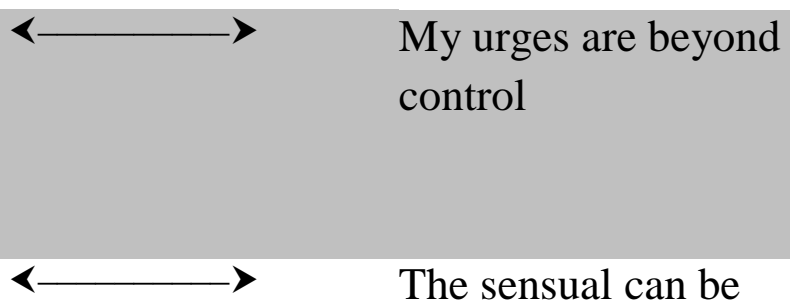

The sensual can be found in each of my senses

I can be full

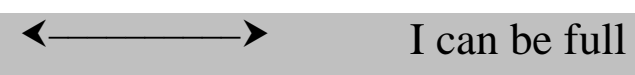

Hungry is my enemy

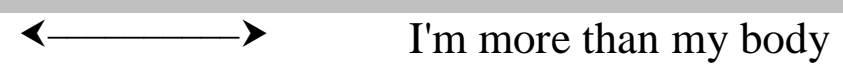

I can control my urges

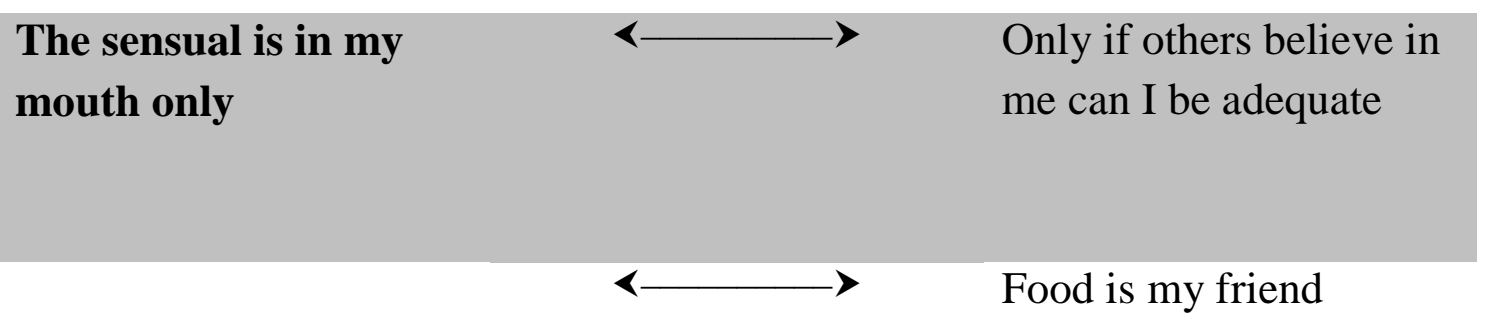

I'm empty

I don't believe in me $\begin{aligned} & \text { Only if others believe in } \\ & \text { me can I be adequate }\end{aligned}$



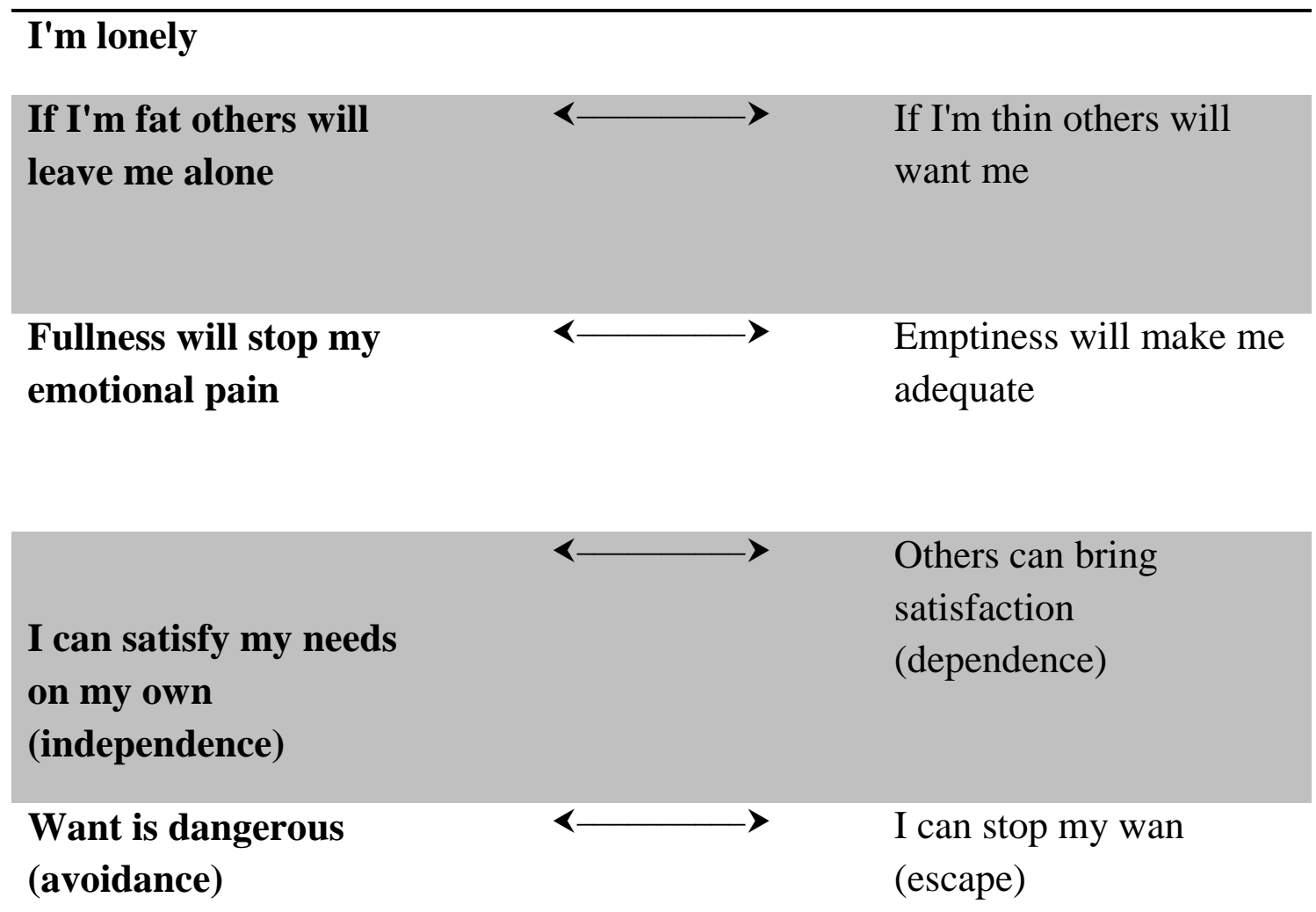

Note: this table quoted from Marra $(2005,129)$.

Thus, the dialectical process of synthesis between body of knowledge from the obese and the lean end of the spectrum can enrich our understanding (Treasure \& et al, 2003). Patients with eating disorders always have fluctuations between the above contradicted thoughts. The role of therapy is reach to synthesis between thesis and antithesis to help patients to get rid of maladaptive thoughts. So, they will be able to monitor and control themselves to achieve adaptation and regulation.

\section{Evidence for adapting DBT as an Effective Treatment for Binge Eating and Bulimia Nervosa:}

There are several studies conducted on patients of eating disorders in general and patients of binge eating and bulimia nervosa. (Salbach-Andrae\& et al ,2008) conducted an intriguing study to describe case series of adolescents with anorexia nervosa and bulimia nervosa who received DBT the effect of DBT, twelve outpatients with anorexia nervosa and bulimia nervosa took part in 25 weeks of twice weekly therapy including individual therapy and skills training group ,family members also involved in the treatment. Posttreatment, significant 
improvements in behavioral symptoms of eating disorder and symptoms of psychopathology were identified. The application of DBT adapted for the treatment of anorexia nervosa and bulimia nervosa among adolescents was associated with a decrease in behavioral symptoms of eating disorders and symptoms of general psychopathology. Also, Klein and colleagues (2013) conducted a study for Targeting binge eating through components of dialectical behavior therapy: Preliminary outcomes for individually supported diary card selfmonitoring versus group-based DBT, the purpose of the study was to examine two condensed adaptations of dialectical behavior therapy (DBT) for binge eating. Women with full- or sub-threshold variants of either binge eating disorder or bulimia nervosa were randomly assigned to individually supported self-monitoring using adapted DBT diary cards (DC) or group-based DBT, each 15 sessions over 16 weeks. The study suggested that with both abbreviated DBT-based treatments, substantial improvement in core binge eating symptoms is possible, enhancing potential avenues for implementation beyond more time-intensive DBT.

Moreover, (Scotti,2014) applied a pilot study to evaluate the efficacy and feasibility of using school-based DBT skills groups for the treatment of adolescent eating disorders and sub-diagnostic disordered eating symptoms. The intervention included 12 weeks of DBT skills groups in a school setting without the inclusion of individual treatment or parent involvement. Results suggest that participation was associated with improvement in behavioral facets of eating disorders and in both externalizing and internalizing symptoms and that use of mobile technology software facilitated data collections. Additionally, Trunko and his colleagues (2017) conducted a pilot open series of lamotrigine in DBT-treated eating disorders characterized by significant affective dysregulation and poor impulse control. Nine women with anorexia nervosa- or bulimia nervosa-spectrum eating disorders in partial hospital or intensive outpatient dialectical behavior therapy (DBT)-based eating disorder treatment took lamotrigine for $147 \pm 79$ days (mean final dose $=161.1 \pm 48.6 \mathrm{mg}$ /day). Participants completed standardized self-report measures of emotion dysregulation and impulsivity after lamotrigine initiation and approximately biweekly thereafter. Mood and eating disorder symptomatology were measured at lamotrigine initiation and at time of final assessment. Results suggested that Lamotrigine and concurrent DBT were associated with large reductions in self-reported affective and behavioral dysregulation $(p s<0.01)$. Eating disorder and mood symptoms decreased moderately.

\section{Conclusion and Future Directions:}

In a nutshell, it has been shown that DBT offers an effective therapeutic approach to treat bulimia nervosa and binge eating. Promising data that collected from various modern evidence supported the effect of this critical therapeutic approach to decrease negative symptoms of eating disorders. The development of DBT 
models and techniques provides a crucial and integrated view to treat different disorders.

It is very important to apply DBT models on other disorders in large communities to achieve the highest level of mental health for patients. So, future research must give attention to this point and try to targeting various disorders because there are many patients who need more attention. When more research will be applied for larger samples, researchers will be able to evaluate the positive effect of this essential approach for treating difficult disorders. 


\section{References}

- Agras,Stewart\&Apple,Robin.(2008). Overcoming Your Eating Disorder: A CognitiveBehavioral Therapy Approach for Bulimia Nervosa and Binge-Eating Disorder,Guided Self-Help Workbook.Oxford University Press.

- American Psychiatric Association.(2013). Diagonistic and Statistical Manual of Mental Disorders $\left(5^{\text {th }}\right.$ ed). Washington,DC.

- Baer,Ruth.(2006). Mindfulness-Based Treatment Approaches: Clinician's Guide Evidence Base and Applications.Massachusetts: Elsevier.

- Belmont,Judith.(2013). 127 More Amazing Tips \& Tools for the Therapeutic Toolbox. Wisconsin. PESI Publishing and Media.

- Boonstra,Jaap.(2004). Dynamics of Organizational Change and Learning. Chichester. John Wiley\&Sons Ltd.

- Brodsky,Beth\& Stanely,Barbara.(2013). The Dialectical Behavior Therapy Primer: How DBT Can Inform Clinical Practice. West Sussex: John Wiley \& Sons.

- Burckell,Lisa\&McMain,Shelley.(2010). Dialectical behavior therapy adapted to the treatment of concurrent borderline personality disorder and substance use disorders.(In). Brizer,David\&Castaneda,Ricardo.(Eds). Clinical Addiction Psychiatry. Cambridge University Press.pp,207-217.

- Champman,Alexander;Gratz.Kim\&Tull,Matthew.(2011). The Dialectical Behavior Therapy Skills Workbook for Anxiety: Breaking Free from Worry, Panic,PTSD\& other Anxiety Symptoms. California: New Harbinger Publications.

- Chen, Eunice;Yiu,Angelina\&Safer,Debra.(2018). Dialectical behavior Therapy and Emotion-Focused Therapies for Eating Disorders.(In). Agras,W\&Robinson,Athena.(Eds). The Oxford Handbook of Eating Disorders.( $2^{\text {nd }}$ edition).Oxford University Press.pp,334350

- Cottone, Rober.(2017). Theories of Counseling and Psychotherapy: Individual and relational Approaches. New York: Springer Publishing Company.

- Insel, Paul;Turner,R\&Ross,Don.(2004). Nutrition ( $2^{\text {nd }}$ ed). Massachusetts. Jones and Bartlett Publishers,Inc.

- Klein, A. S., Skinner, J. B., \& Hawley, K. M. (2013). Targeting binge eating through components of dialectical behavior therapy: Preliminary outcomes for individually supported diary card self-monitoring versus group-based DBT. Psychotherapy, 50(4), 543. 
- Klein,Dena\& Miller,Alec.(2011). Dialectical Behavior Therapy for Suicidal Adolescents with Borderline Personality Disorder. (In).

Peter,Todd\&Freeman,Jennifer.(Eds). Cognitive-Behavioral Therapy in Youth:An Issue of Child and Adolescent Psychiatric Clinics of North America. Pennsylvania: Elsevier, Inc. Pp,205-216.

- Koerner,Kelly.(2012). Doing Dialectical Behavior Therapy: A Practical Guide. New York: The Guilford Press.

- Linehan,Marsha\& Wagner,Amy.(2006). Applications of Dialectical Behavior Therapy to Posttramatic stress disorder and related Problems. (In).Follette,Victoria\&Ruzek,Josef.(Eds). Cognitive Behavioral Therapies for Trauma.( $2^{\text {nd }}$ edition). New York: The Guilford Press. pp.117-146.

- Linehan,Marsha\&Mazza,Elizabeth.(2008). Dialectical Behavior Therapy.(In).Barlow,David.(Ed). Clinical Handbook of Psychological Disorders: A Stepby-Step Treatment Manual.( $4^{\text {th }}$ edition). New York: The Guilford Press. pp,365-420.

- Linehan,Marsha;Miller,Alec\&Rathus,Jill.(2007). Dialectical Behavior Therapy with Suicidal Adolescents.New York: The Guilford.

- Lozier, Carol.(2018). DBT Therapeutic Activity Ideas for Working with Teens: Skills and Exercises for Working with Clients with Borderline Personality Disorder, depression, Anxiety, and Other Emotional Sensitivities. Jessica Kingsley Publishers: London.

- Marra,Thomas.(2005). Dialectical Behavior Therapy in Private Practice: A Practical \& Comprehensive Guide. California: New Harbinger Publications, Inc.

- Mcintosh,Virginia;Jordan,Jennifer; Carter,Janet;Latner,Janet\& Wallace,Alison.(2007). Appetite-Focused Cognitive-Behavioral Therapy for Binge Eating.(In).

Latner,Janet\&Wilson,Terence. (Eds). Self-Help Approaches for Obesity and Eating Disorders: Research and Practice.New York: The Guilford.pp,325-346.

- Mills, Jon.(2010). Origins: On the Genesis of Psychic Reality. McGill-Queen's University Press.

- Norling,Darcy\&Kim,Soonie.(2010). Borderline Personality

Disorder.(In).Thomas,Jay\&Hersen,Michel.Handbook of Clinical Psychology

Competencies.(Eds).New York: Springer Science+ Business Media, LLC. pp,877-900.

- Pederson, Lane.(2013). DBT Skills Training for Integrated Dual Disorder Treatment Settings. Michigan:PESI Publishing \& Media.

- Pederson, Lane.(2015). Dialectical Behavior Therapy: A Contemporary Guide for Practitioners. West Sussex: John Wiley \& Sons,Ltd. 
- Porr, Valerie.(2010). Overcoming Borderline Personality Disorder: A Family Guide for Healing and Change. Oxford University Press.

- Safer, Debra;Adler,Sarah\&Masson,Philip.(2018). The DBT Solution for Emotional Eating: A Proven Program to Break The Cycle of Bingeing and Out-of-control Eating. The Guilford Press: New York.

- Safer,Debra;Adler,Sarah\&Masson,Philip.(2018). The DBT Solution for Emotional Eating: A Proven Program to Break the Cycle of Bingeing and Out-of-Control Eating. New York: The Guilford Press.

- Salbach-Andrae, H., Bohnekamp, I., Pfeiffer, E., Lehmkuhl, U., \& Miller, A. L. (2008). Dialectical behavior therapy of anorexia and bulimia nervosa among adolescents: A case series. Cognitive and behavioral practice, 15(4), 415-425.

- Scotti, J. F. (2014). School-based DBT skills groups for adolescent eating disorders and body image concerns: a pilot study.(Ph.D). University of Montana. Missoula.

- Stone, Susan.(2007). Using Dialectical Behavior Therapy in Clinical Practice: Client Empowerment, Social Work Values. (In). Ronen, Tammie \& Freeman ,Arthur.(Eds). Cognitive Behavior Therapy in Clinical Social Work Practice.New York: Springer Publishing Compay.pp,147-166.

- Sue,David\&Sue,Diane.(2008). Foundations of Counseling and Psychotherapy: Evidence-Based Practices for a Diverse Society. New Jersey: John Wiley \& Sons.

- Swales,Michaela\&Heard,Heidi.(2009). Dialectical Behaviour Therapy: Distinctive Features. New York: Routledge.

- Treasure,Janet;Schmidt,Ulrike\&Furth,Eric.(2003). Handbook of Eating Disorders.(2 ${ }^{\text {nd }}$ edition). West Sussex: John Wiley \& Sons.

- Trunko, M. E., Schwartz, T. A., Berner, L. A., Cusack, A., Nakamura, T., Bailer, U. F., ... \& Kaye, W. H. (2017). A pilot open series of lamotrigine in DBT-treated eating disorders characterized by significant affective dysregulation and poor impulse control. Borderline personality disorder and emotion dysregulation, 4(1), 21.

- Twohig,Michael\&Peterson,Katherine.(2009). Distress Tolerance.(In). O'Donohue,William\&Fisher,Jane.(Eds). General Principles and Empirically Supported Techniques of Cognitive Behavior Therapy.New Jersey: John Wiley \& Sons,Inc. Pp,265271.

- Weder,Natalie.(2010). Dialectical Behavioral Therapy.(In). Tampi,Rajesh;Muralee,Sunanda;Weder,Natalie\&Wilkins,Kirsten.(Eds). Clinical 
Assessments in Psychiatry: Mastering Skills and Passing Exams.Philadelphia: Wolters Kluwer.Pp,182-184.

- Yager,Joel\&Powers,Pauline.(2007). Clinical Manual of Eating Disorders. Washnigton: American Psychiatric Publishing, Inc. 